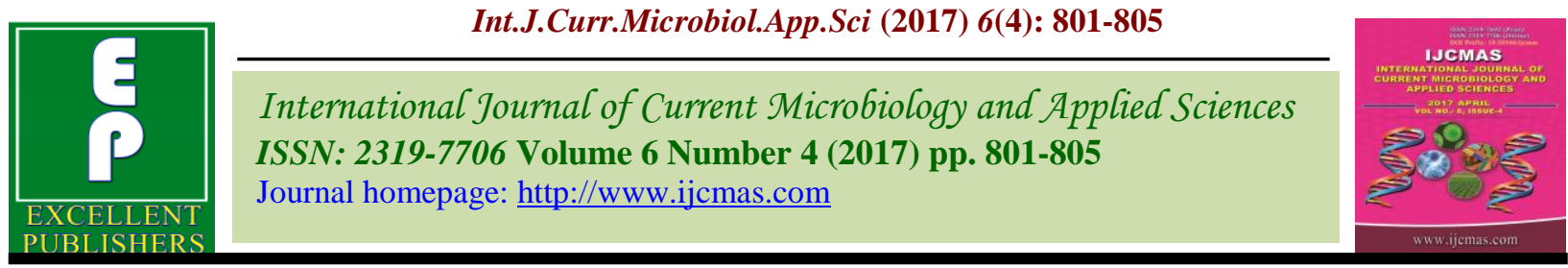

Original Research Article

https://doi.org/10.20546/ijcmas.2017.604.100

\title{
Detection of Gastrointestinal Helminthic and Protozoan Infections in Diarrhoeic Goats
}

\author{
S. Saravanan* and K.M. Palanivel \\ Department of Veterinary Preventive Medicine, Veterinary College and Research Institute, \\ Tamil Nadu Veterinary Animal Sciences University, Namakkal-637 002, Tamil Nadu, India \\ *Corresponding author
}

\begin{tabular}{|c|c|}
\hline & A B S T R A C T \\
\hline $\begin{array}{l}\text { Gastro-intestinal } \\
\text { parasitism, } \\
\text { Incidence, } \\
\text { Diarrhoeic goats, } \\
\text { Eimeria spp, } \\
\text { Mixed infection. }\end{array}$ & \multirow{3}{*}{$\begin{array}{l}\text { Clinical parasitism occurs less frequently in goats, however, the parasites of the } \\
\text { stomach and intestine could lead to scouring, dehydration, anemia, depression and } \\
\text { eventually death. The incidence of gastro-intestinal helminthic and protozoan } \\
\text { parasites was identified by coprological survey made in diarrhoeic goats brought } \\
\text { to the Teaching Veterinary Clinical Complex (TVCC), Veterinary College and } \\
\text { Research Institute, Namakkal. The study revealed the incidence of gastrointestinal } \\
\text { parasites predominantly by Eimeria spp. and Strongylus spp. followed by } \\
\text { Moniezia spp., Strongyloides spp., and Trichuris spp. Mixed infections were found } \\
\text { for all the above parasites, predominantly with Strongylus and Eimeria. } \\
\text { Prevalence of gastrointestinal parasitism was high in male and in less than } 2 \\
\text { months old kids. }\end{array}$} \\
\hline Article Info & \\
\hline $\begin{array}{l}\text { Accepted: } \\
\text { 06 March } 2017 \\
\text { Available Online: } \\
12 \text { April } 2017\end{array}$ & \\
\hline
\end{tabular}

\section{Introduction}

Parasitic gastro-enteritis leads to a serious health threat with a limitation to the productivity of small ruminants due to the associated morbidity, mortality, cost of treatment and prophylaxis (Nwosu et al., 2007). Parasitic infections are of much economic importance because small ruminants' rearing has become a major source of income particularly to the marginal farmers in the country (Pathak and Pal, 2008). The most important gastro intestinal parasites in goats are coccidia (protozoa), nematodes (roundworms), cestodes (tapeworms), and trematodes (flukes). Amongst these, parasites of Trichostrongylidae family are considered of paramount importance as they cause significant morbidity and loss of production (Veale, 2002).

In this situation, the control of gastrointestinal trichostrongylosis in goats is found to be severely impaired by the increasing development of anthelmintic resistance (Sangster, 2001) and resistance is found have reported worldwide for three main broad spectrum anthelmintics commonly available for the control of trichostrongyles (Silvestre $e t$ $a l$. , 2002). Goats have numerous internal parasites and one of the most important are the coccidian species (Dai et al., 2006). This paper reports the incidence of clinical parasitism in the stomach and intestine, of the 
diarrhoeic goats brought to the TVCC of this institute.

\section{Materials and Methods}

Faecal samples were collected from a cross section of 120 non-descriptive goats in different age groups and both sex brought to the Teaching Veterinary Clinical Complex, Veterinary College and Research Institute, Namakkal from December, 2015 to March, 2016, with the history of diarrhoea (Fig 1 and2) and management under semi-intensive system. Faecal examination was carried out by flotation and centrifugal sedimentation technique and the endoparasitic eggs were identified based on the morphology (Soulsby, 1982).

\section{Results and Discussion}

Out of 120 diarrhoeic cases studied, the incidence of helminthic, coccidian and mixed infections (cestode, nematode and coccidian) accounted for 56.6 (68 cases) and 55.0 (66 cases) and $10.0 \%$ (12 cases) of the cases, respectively (Fig 3). Out of these 120 diarrhoeic goats, 66 cases $(55.0 \%)$ harboured Eimeria sp., 48 cases (40.0\%) Haemonchus contortus, 14 cases (11.6\%) Moniezia sp., 4 cases $(3.3 \%)$ Strongyloides papillosus and 2 cases $(1.6 \%)$ Trichuris ovis. Mixed infections were detected for $H$. contortus and Eimeria sp. in 6 cases (5.0\%), Moniezia and Eimeria sp. in 2 cases $(1.7 \%), S$. papillosus, $H$. contortus and Eimeria sp. in 2 cases (1.7\%) and Moniezia sp. and $H$. contortus in 2 cases $(1.7 \%)$.

Male goats were found to be highly susceptible in this study with an incidence of $60.0 \%$ (72 cases) than females with an incidence of $40.0 \%$ (48 cases). The occurrence was also found to be high in the young kids with the age group of less than 2 months with an incidence of $43.3 \%$ (52 cases) followed by 2-4 months with $26.7 \%$ (32 cases), 4-6 months with $15.0 \%$ (18 cases), 6 months to 1 year with $8.3 \%$ (10 cases) and above 1 year with $6.7 \%$ ( 8 cases).

Fig.1 A Goat positive for Eimeria species showing watery diarrhoea with tenesmus

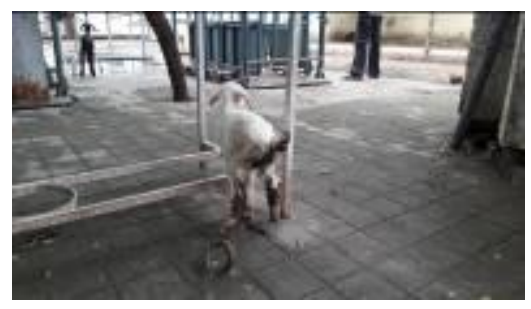

Fig.2 Diarrhoeic faeces showing the mature proglottids of Moniezia species

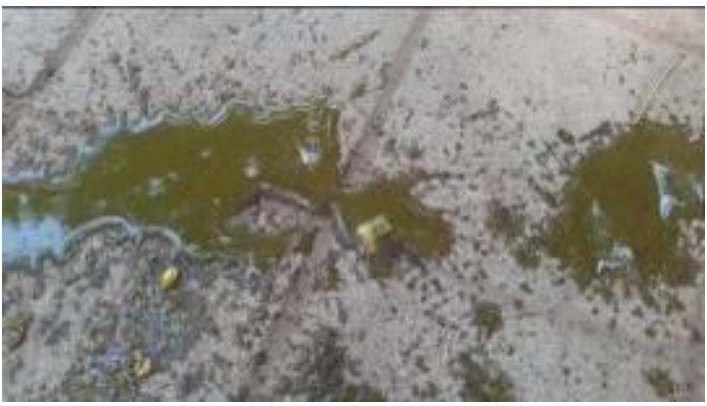


Fig.3 Gastro intestinal parasitic eggs and coccidian parasites from the faecal samples of diarrhoeic goats

a) Unsporulated oocysts of Eimeris sp (40x) b) Ova of Moniezia sp (40x)

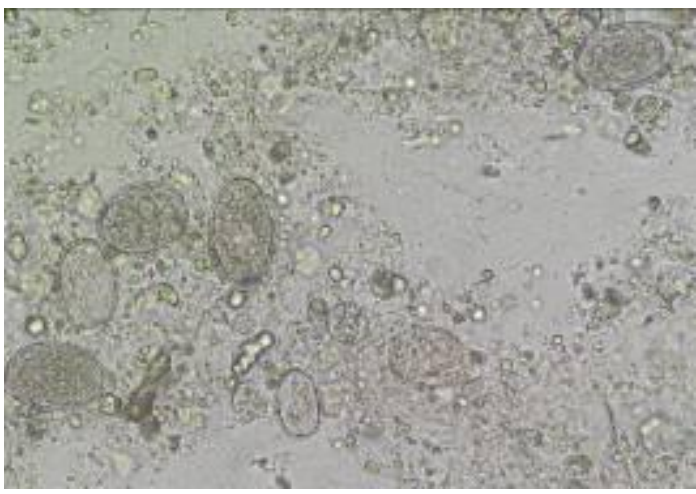

c) Egg of Strongyle sp (40x)

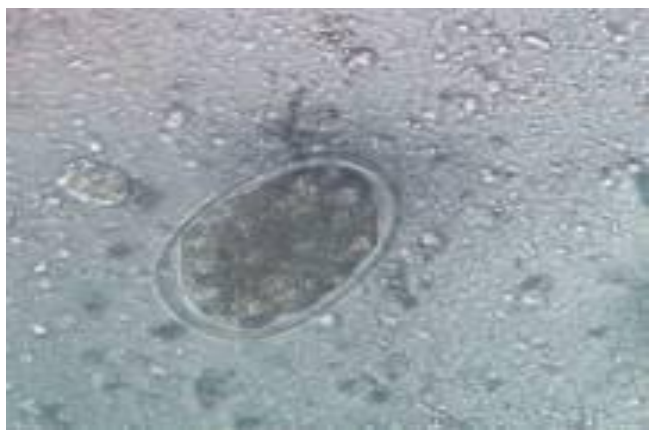

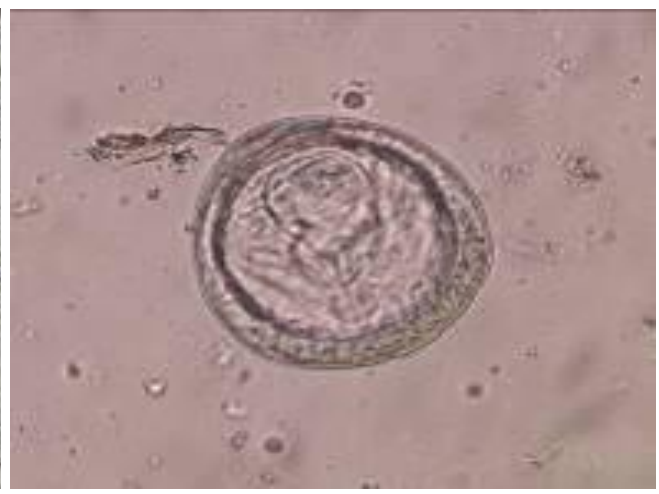

d) Egg of Strongyloides sp (40x)

e) Egg of Trichuris sp (40x)

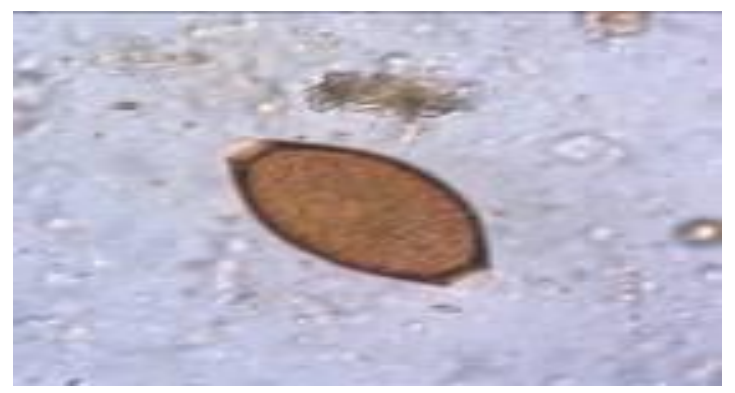

In this study, coccidian sp. was found to be the most commonly found parasite followed by strongyles, Moniezia, Strongyloides sp. and Trichuris sp. in diarrhoeic goats and this finding is in accordance with that of Velusamy et al., (2015) who also recorded the

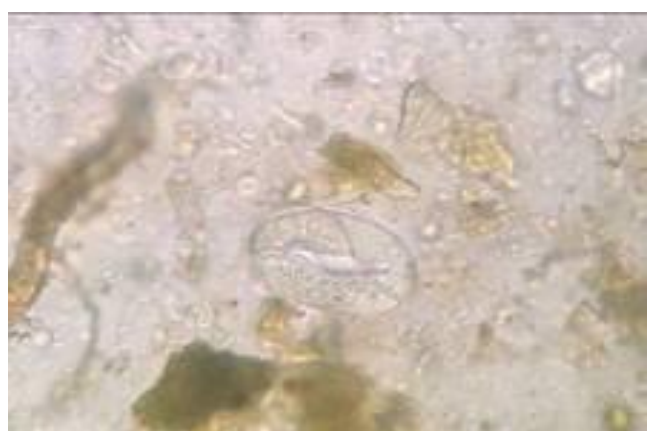

highest prevalence for coccidia, followed by strongyles, Moniezia, Trichuris and least with amphistome in both the sheep and goats in North-western part of India. In contrast, Singh et al., (2013) observed the bursate worms to be most prevalent in goats in Madura, India 
with a higher prevalence of Haemonchus (53.34\%), a lower prevalence of coccidian $(23.34 \%)$ and mixed parasitic infections $(23.34 \%)$ in goats than that observed in this study. In contrast to this study, Sutar et al., (2010) also recorded a high prevalence of Trichuris sp. (18\%) and Strongyloides sp. $(21.25 \%)$, however a low prevalence of Moniezia sp. (5.5\%) in Maharastra of India. Previous workers reported high and varying rates of parasitic infestation throughout the year in goats and the variation in prevalence depends upon difference in agro-climatic conditions and availability of susceptible hosts (Pandey et al., 1994). The high incidence of coccidian species in this study could be attributed to the high relative humidity and ambient temperature available during this rainy (North-east) and winter season for the sporulation of the oocysts in the unhygienic pens where the animals are overcrowded. This conductive climate could also favor the development and survival of eggs and infective larval stages of the strongyles.

In this study, mixed infections were detected for strongyles (Haemonchus sp) with Eimeria sp., Strongyloides sp. and Moniezia sp., as previous studies also reported Moniezia infection along with bursate worm infections in goats and sheep in India and abroad (Katoch et al., 1998 and Singh et al., 2013). The occurrence of gastrointestinal parasitism was high in males than females in this study, where as Sutar et al., (2010) recorded a higher prevalence in females $(69.05 \%)$ than in males $(54.80 \%)$.

In the present study, the coccidia were the commonly encountered parasites in the diarrhoeic goats followed by strongyles during the North-east monsoon and winter. With this view, sanitation of the animal house, periodical faecal examination and timely treatment with anthelmintics or anticoccidials would help in halting the spread of these parasites and thereby improving the economy of the marginal farmers.

\section{Acknowledgement}

The authors express their gratitude to the Dean, Veterinary College and Research Institute, Namakkal for providing necessary facilities in this study.

\section{References}

Dai, Y., X. Liu, M. Liu, and Tao, J. 2006: Pathogenic effects of the coccidium Eimeria ninakohlyakimovae in goats. Vet. Res. Commun., 30: 149-160.

Katoch, R., S. Mittra R.K. Agnihotri and Sharma, A.K. 1998. Strongylosis in sheep and goats at high altitude: a sporadic occurrence. Indian Vet. J., 75(4): 326-362.

Nwosu, C.O., P.P. Madu and Richards, W.S. 2007. Prevalence and seasonal changes in the population of gastrointestinal nematodes of small ruminants in the semi-arid zone of North-Eastern Nigeria. Vet. Parasitol., 144: 118-124.

Pathak, A.K and Pal, S. 2008. Seasonal prevalence of gastrointestinal parasites in goats from Durg district of Chhattisgarh. Vet. World, 5: 136-137.

Pandey, V.S., M. Ndao and Kumar, V. 1994 Seasonal prevalence of gastrointestinal nematodes in communal land goats from high yield of Zimbabwe. Vet. Parasitol., 51: 241-248.

Sangster. N.C. 2001. Managing parasiticide resistance. Vet. Parasitol., 89-109.

Singh, V., Varshney, P. Dash, S.K. and Lal H.P. 2013. Prevalence of gastrointestinal parasites in sheep and goats in and around Mathura, India. Vet. World, 6(5): 260-262.

Silvestre, A., Leignel, V., Berrag, B., Gasnier, 
N., Humbert, J.F., Chartier, C. and Cabaret, J. 2002. Sheep and goat nematode resistance to anthelmintics: pro and cons among breeding management factors, Vet. Res., 33: 465480.

Soulsby, E.J.L. 1982. Helminths, Arthropods and Protozoa of Domestic Animals. $7^{\text {th }}$ edn. The English Language Book Society and Bailliere Tindall, London, pp. 788.

Sutar, A.U., S.B. Kengar, S.S. Patil and Khan, M.R. 2010. Prevalence of Gastrointestinal Parasites in Goats of Ahmednagar district of Maharashtra. Vet. World, 3(10): 456-457.

Veale, P.I. 2002. Resistance to macrocyclic lactones in nematodes of goats. Australian Vet. J., 80: 303-304.

\section{How to cite this article:}

Saravanan, S. and Palanivel, K.M. 2017. Detection of Gastrointestinal Helminthic and Protozoan Infections in Diarrhoeic Goats. Int.J.Curr.Microbiol.App.Sci. 6(4): 801-805. doi: https://doi.org/10.20546/ijcmas.2017.604.100 